\title{
Translational Medicine - New Frontiers in Cardiology
}

\author{
Protásio Lemos da Luz ${ }^{10}$ and Claudio Tinoco Mesquita2 ${ }^{(1)}$ \\ Universidade de São Paulo, ' São Paulo, SP - Brazil \\ Universidade Federal Fluminense, ${ }^{2}$ Niterói, $R J$ - Brazil
}

"A scientist is happy, not in resting on his attainments but in the steady acquisition of fresh knowledge."

Max Planck

Translational medicine is defined by the European Society for Translational Medicine(EUSTM) as "an interdisciplinary branch of the biomedical field supported by three main pillars: benchside, bedside, and community. ${ }^{1}$ Frequently, translational medicine dedicated to cardiology is known as translational cardiology. The International Journal of Cardiovascular Sciences is dedicating a special thematic issue on translational cardiology due to the significant importance of this field in the last years. Searching PubMed for the keywords "translational" and "cardiology," the number of papers on translational cardiology were no more than 10 per year in mid-80's, with an increase to around 50 papers per year in mid-90's, 200 articles per year in the 2000's and, thereafter, a significant exponential increase in the absolute number of publications, close to 2,000 papers/year in 2019 (Figure 1). Cardiac journals are increasingly accepting translational papers covering different aspects of this exciting field, so diverse as cardiotoxic mechanisms ${ }^{2}$ targeting RNA with antisense oligonucleotides and small interfering RNA in amyloidosis ${ }^{3}$ or nitrosative stress as a modulator of inflammatory change in Takotsubo Syndrome ${ }^{4}$ to name a few.

In this special edition, we present articles covering many areas in Cardiology, but with a common denominator: translational medicine. Intentionally, we covered several

\section{Keywords}

Translational Medicine/ trends; Translational Medical Research/trends; Basic Research/trends; Implementation Science/ trends; Access health technologies and informations/ trends.

\section{Mailing Address: Claudio Tinoco Mesquita}

Universidade Federal Fluminense Faculdade de Medicina - Departamento de Radiologia

Av. Marques do Paraná, 303. Postal Code: 24230-322, Centro, Niterói,

RJ - Brazil

E-mail: claudiotinocomesquita@id.uff.br

DOI: https://doi.org/10.36660/ijcs.20200259 areas, from genetic/epigenetic to treatment of arrhythmias. The reason for this approach is that the intrinsic concept of translational medicine is not restricted to a single specialty; indeed, it applies to all areas of knowledge and their applications. The concept of translational medicine emerged and continues to evolve based on frequent observations, findings originated from hypothesis and laboratorial research, both in vitro and in vivo, but consumed decades before reaching the clinical arena. On the other hand, many original clinical observations remained without clarification of their basic mechanisms, either cellular, molecular or genetics. As a result, important clinical findings were considered "anecdotal" for considerable periods of time until mechanistic and trustful clinical studies were performed. Hence, significant clinical findings were never implemented in a broad sense; on the other hand, myth persisted until time demonstrated they were nothing more than myths. Evidently, these two circumstances contributed to the slow progress in medical care, i.e., on one hand, unrecognized truths, and proclaimed fallacies on the other. Lately, another question appeared, namely, the application of knowledge not only to the individuals but to the whole population as well. This closes the circle of translation: from basics to clinical application; from clinical observation to laboratory studies of their causes and mechanism. Finally, from knowledge generation to population uses. Thus, translational medicine deals with this complex array of hypothesis, rigorous scientific testing and population applicability.
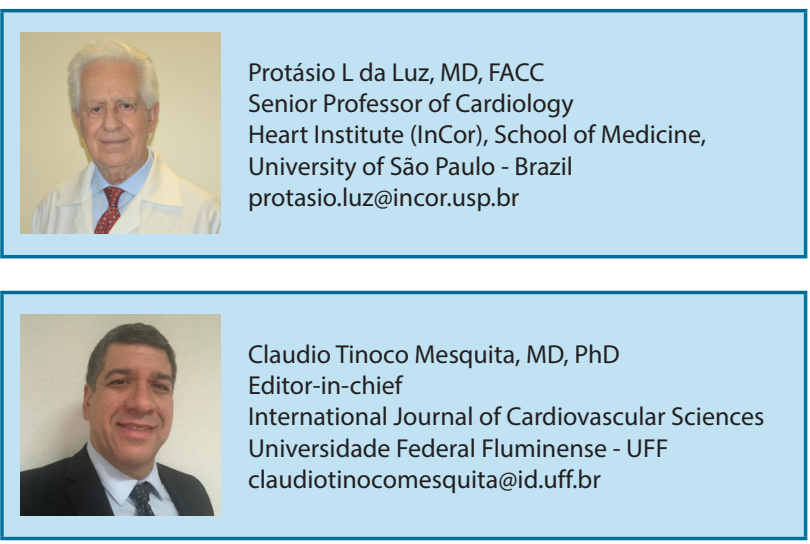
Academic institutions are already reviewing organizational structures, promoting innovative polices, to implement this concept. Under such concept, basic researches and clinical investigators must collaborate tightly and carry on investigative programs. This requires structural modifications in universities and research institutes. These changes depend on specific institutional policies; individual actions are not sufficient. In other words, we need profound philosophical modifications and, consequently, administrative policies in order to materialize the translational concept. Such materialization of the translational concept will accelerate scientific progress and its clinical application.

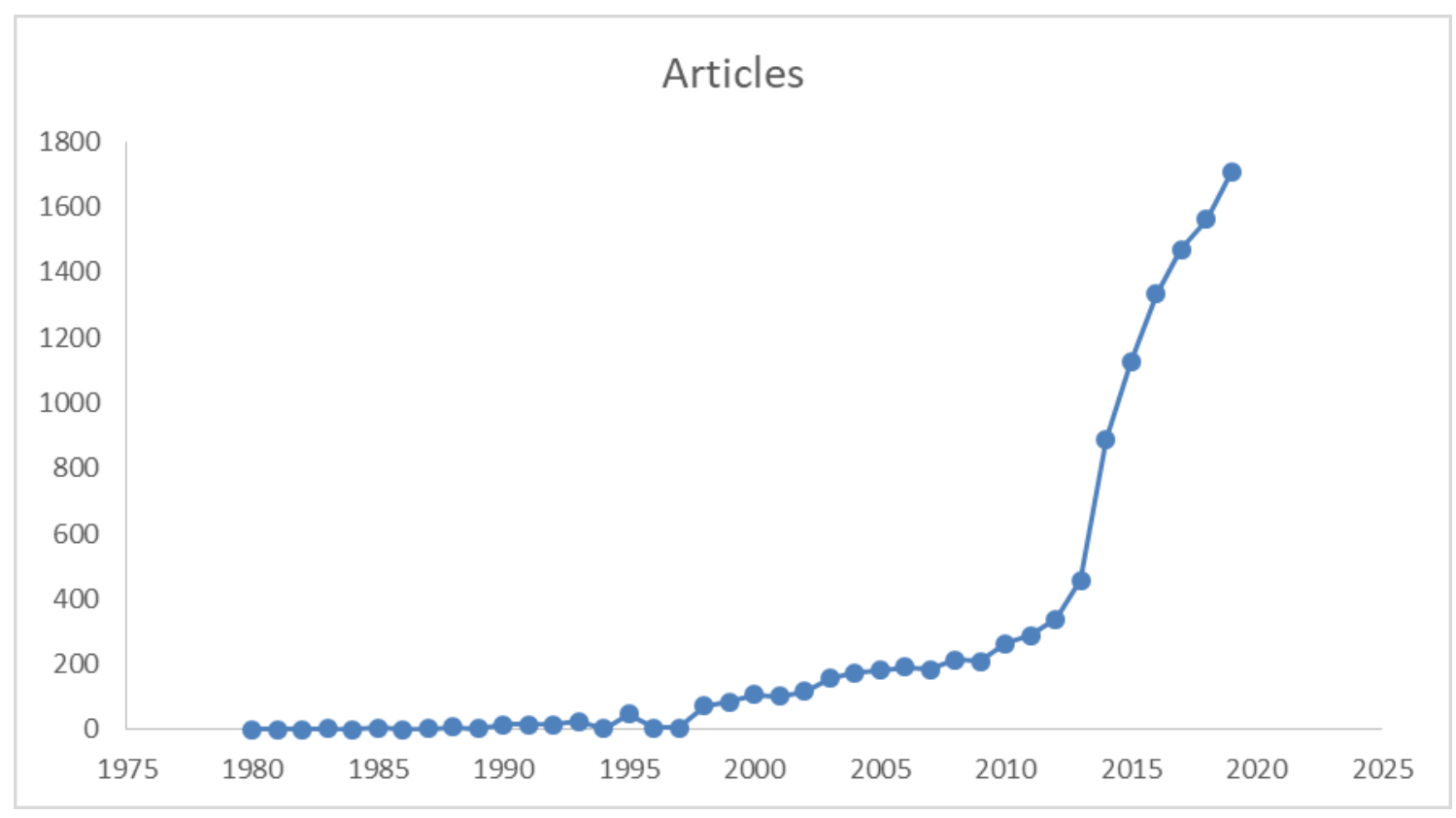

Figure 1 - Number of articles related to the term "translational and cardiology" that were indexed by PubMed per year (data extracted from PubMed).

\section{References}

1. Cohrs RJ, Martin T, Ghahramani P, Bidaut L, Higgins PJ, Shahzad A. Translational medicine definition by the European society for translational medicine. New Horizons Transl Med [Internet]. 2015;2(3):86-8. Available from: http://dx.doi.org/10.1016/j.nhtm.2014.12.002

2. Lobenwein D, Kocher F, Dobner S, Gollmann-Tepeköylü C, Holfeld J. Cardiotoxic mechanisms of cancer immunotherapy - A systematic review. Int J Cardiol [Internet]. 2020 Aug;709:136126. Available from: https://doi.org/10.1016/j.scitotenv.2019.136126
3. Katzmann JL, Packard CJ, Chapman MJ, Katzmann I, Laufs U. Targeting RNA With Antisense Oligonucleotides and Small Interfering RNA: JACC State-of-the-Art Review. J Am Coll Cardiol. 2020;76(5):563-79.

4. Surikow SY, Nguyen TH, Stafford I, Chapman M, Chacko S, Singh K, et al. Nitrosative Stress as a Modulator of Inflammatory Change in a Model of Takotsubo Syndrome. JACC Basic to Transl Sci. 2018;3(2):213-26. 